\title{
Futuristic Technologies for Smart Toilets in Smart Cities
}

\author{
Manvita Asnodkar ${ }^{1}$ \\ (M.Tech Student) \\ Electronics Department \\ Sanjay Ghodawat University \\ Kolhapur, Maharashtra, India. \\ Dr. Prasanjeet Patil ${ }^{3}$ \\ (Associate Professor) \\ Electronics Department \\ Sanjay Ghodawat University \\ Kolhapur, Maharashtra, India.
}

\author{
Dr. Nilesh Bahadure ${ }^{2}$ \\ (Professor) \\ Electronics Department \\ Sanjay Ghodawat University \\ Kolhapur, Maharashtra, India. \\ Uma Pujari ${ }^{4}$ \\ (M.Tech Student) \\ Electronics Department \\ Sanjay Ghodawat University \\ Kolhapur, Maharashtra, India.
}

\begin{abstract}
Public Toilets have always been a topic of concern. In this innovative world, where all the countries are advancing in their developments and making smart cities, yet the cleanliness and hygiene in our nation is under threat. The public toilets have been established in many parts of the country but they are not maintained well. Due to ill maintenance, the air in the toilets and the surrounding area is not clean and there is bad odor. Hence even though there are many toilets, people do not use the toilets and prefer to excrete in the open environment or near the rivers. Consequently, this causes pollution in our country and spreads more diseases to the living beings. In this paper, new innovative technologies that have been implemented in making of automatic and smart toilets have been discussed. This paper also considers energy conservation techniques that can be used in smart toilets.
\end{abstract}

Keywords - Smart toilets, IoT, image processing, water and energy conservation.

\section{INTRODUCTION}

In today's world, the technologies are being drastically developed, yet the cleanliness in our nation is under major risk. In our country, our Indian Government has introduced the Swachh Bharat (Clean India) Mission, a massive campaign to clean up the country's cities, towns and rural areas. One of the objectives of Clean India Mission is to keep the toilets contamination free. Also, the energy is one of the most important building blocks in human development, and as such, acts as a key factor in determining the economic development of all the countries [1].

The new applications of Internet of Things (IoT) are enabling the Smart City Project initiatives worldwide. It has the ability to monitor remotely, manage and control devices, and to create new insights and actionable information from massive streams of real-time data. The smart city services can be improved by managing water, waste, energy consumption, air quality, traffic, parking, weather condition, noise pollution. The Smart City Mission in India under the Ministry of Urban Development is an urban renewal and retrofitting program by the Government of India with the mission to develop 100 smart cities across the country making them citizen friendly and sustainable.
The basic requirements for the ecological development in a smart city are the water management and energy conservation. In this paper, some of the new innovative technologies that have been used in making of automatic and smart toilet system have been examined by taking into consideration the basic requirements for ecological development in smart city.

\section{LITERATURE REVIEW}

\section{A. Smart and automatic technologies developed}

Sarode [2] in the paper designed and fabricated an automatic flush system for sanitation using microcontroller and IR sensor technology. The system is designed to use $\mathrm{pH}$ sensor for identifying the change in the purity of water and activates the controllable flushing system. Tsai et al. [3] designed and implemented an auto flushing device with ultralow standby power consumption. The system uses sensor, low-power chips and state control mechanism to save power when no user is using the toilet. The system consumes $10 \mathrm{~mW}$ which is very low power while the other systems consume 0.5 to $1 \mathrm{~W}$ of power when no user is present for 24 hours a day.

Elavarasi et al. [4] in the paper proposed and developed a smart toilet using IoT. The authors proposed a microcontroller based system to keep the toilets clean by detecting dirt and to observe the sweeper's working activities using IoT and image processing. Elakiya et al. [5] designed and implemented a smart toilet using IoT embedded sensor devices to detect dirt in the toilet, gas detection and the presence of sweeper. The system also detects the depth of the septic tank and sends a message to a particular organization.

In the paper, Smart toilets using BLE beacon technology by N. Mishra et al. [6] developed an application of smart toilets using Bluetooth low energy beacons and readers technology for the management of public toilets by government. The system counts the number of users using the toilet and the data is stored in cloud database for performing monthly analysis. Boonyakan et al. [7] in the paper, investigated in one of the public toilets on how much clean water to be used for cleaning the toilet bowl. After 
investigation, the results were shown that duration of 3.8 seconds was sufficient for flushing water in the toilets.

Smart toilet mechanism is very important especially in rural areas. Mithya et al. [8] proposed a technique for smart toilets using turbidity sensor to sense the bacteria in the toilet and identifying dirt in toilets and monitoring the sweeper's working activities. If the bacteria is sensed or dirt is identified then the alert message is send to the sweeper. Sonekar et al. [9] proposed a system of smart sensible washrooms to optimize the manpower and real-time tracking of toilet condition in term of odour level and user count, and turning on/off lights using different sensors like ammonia sensor, PIR sensor, buzzer, LCD display.

The automatic urinal flushing system has been developed in the market for a long time but none of them is smart. In $[10,11]$, Osathanunkul et al. designed and implemented an automatic smart urinal flusher system to provide the usage information to a caretaker to estimate and analyze the number of users in each day or week, and which urinal has been used the most, so that more care can be taken of it. The authors also found the most satisfied parameter for users while spending clean water as less as possible by configuring the timing of the flushing using MQTT communication protocol. The results of the test environment showed a flush duration of 2.5 seconds was enough to satisfy most of the users. Muntashar et al. [12] in the paper smart urinal mech-automatic flush developed an automatic system to provide water level information to the caretaker. It starts flushing automatically when object or obstacles are detected and if any odor is detected the fragrance device activates automatically.

Ashiq et al. [13] in the paper designed and fabricated the semi-automated pressurized flushing system in the toilets in Indian Railways. The system is designed and fabricated in such a way that the water is flushed only when the passenger opens and closes the door, which reduces the wastage of water and keeps the toilet clean. Katariya et al. [14] in the paper Smart toilet proposed a toilet system to maintain hygienic level of Railway toilets through automation with the help of IoT. The proposed system automatically cleans the squat pan toilet with the help of robotic arm, by using sequential cleaning algorithm.

\section{B. Health Monitoring while using Smart Toilets}

Developments in medical science and technologies, medicines and public health combined with increased consciousness about nutrition and personal hygiene have progressed the way for the drastic increase in life expectancy globally. S. Sangwan [15] proposed an IoT based smart toilet which easily tests user body waste and helps to track and share the reports to the doctor to guide the user on how to improve his health and to maintain the privacy, user's profile and sessions are maintained. Urine tests can be performed to compare the color of test strips. In this paper [16], colorimetric detection method is proposed in the system which evaluates the captured image of the strip in various color spaces. The name of the proposed strip is Doughnut-shaped Nearness Urine Tester (DONUT), and it allows rapid assessment and with no requirement of calibration which makes it easy for end user. The results can also be delivered on the smartphone.

By using RGB sensors and Spectrophotometric analysis, a special toilet system with a new sensor system was designed [17]. Through this system, people can check for their health status if suffering from any diseases which can be done by analyzing of the urine components. Using long-range wireless communication technology, the results can be sent to the user from the smart toilet. Huang et al. [18] developed the smart toilet equipment with measurements of physiological parameters including ECG, body weight and body fat ratio and also provide health management function. The electrodes are mounted on toilet seat and are used for measuring ECG and bioelectrical impedence.

\section{Use of solar power for generation of electricity}

Solar power for generation of electricity is increasing its importance as it is a renewable energy and is available in abundance. In [19], the proposed system deals with the generation of electricity using solar power by properly orienting the panel in accordance with the position of the sun. The working is based on stepper motor moving intelligently the panel according to the intensity of light using light sensor. Since non-renewable energy is limited, the upcoming generation might have to face energy crisis if alternate sources of energy is not developed. In [20], authors have proposed a substitute of 10-watt conventional night lamp of the same intensity. The paper gives the importance of replacing a conventional night lamp in every house by solar night lamp.

Umer et al. in the paper [21] designed and optimized Solar Carport Canopies for maximum power generation and efficiency at Bahawalpur. In this project, solar car parking lots were implemented. The detailed work has been done for solar car parking site selection and maximum solar electric power generation and the capacity effects. The experiment was performed at different standard tilt angles to produce maximum solar photovoltaic energy.

\section{CONCLUSION}

Based on the above literature review, the following conclusions were made. The smart public toilets can be implemented using the latest technologies. If the toilets are clean and maintained well, the users will increase and help in keeping the environment clean. The maintenance of the toilet can be monitored at the organization by sending the data to the organization application. The toilets built in a smart way can help reduce the pollution. Smart toilets will help people in identifying the diseases which the users are unaware. The smart toilets can use the solar energy which can help in energy conservation.

\section{ACKNOWLEDGMENT}

"The Project has been funded by The Institution of Engineers (India), 8 Gokhale Road, Kolkata 700020 under R\&D Grant-in-Aid scheme". Special thanks to the organization for supporting financially. 


\section{REFERENCES}

[1] "Energy Statistics", Central Statistics Office, Publication report, Twenty Fifth Issue, 2018.

[2] Parth M. Sarode, "Design and Implementation of Automatic Flush System for Sanitation in Public Toilets", International Journal of Researches in Biosciences, Agriculture and Technology, Vol. II, Issue7, Nov 2015, pp. 56-58.

[3] C. Tsai, Y. Bai, M. Lin, R. J. R. Jhang and Y. Lin, "Design and implementation of an auto flushing device with ultra-low standby power," 2013 IEEE International Symposium on Consumer Electronics (ISCE), Hsinchu, 2013, pp. 183-184.

[4] K. Elavarasi, V. Suganthi and J. Jayachitra, "Developing Smart Toilets Using IoT", International Journal of Pure and Applied Mathematics, Vol-119, No. 15, 2018, pp. 611-618.

[5] E. Elakiya, K. Elavarasi, R. P. Kaaviya Priya, "Implementation of Smart Toilet (Swachh Shithouse) using IoT Embedded Sensor Devices", International Journal of Technical Innovation in Modern Engineering \& Science, Vol-4, Issue-4, April 2018, pp. 65-74.

[6] N. R. Mishra, P. M. Suri and S. Chopra, "Smart Toilets using BLE Beacon Technology," 2018 3rd International Conference on Communication and Electronics Systems (ICCES), Coimbatore, India, 2018, pp. 799-802.

[7] K. Boonyakan, N. Heamra and A. Changkamanon, "Water efficient toilet: Setting a suitable automatic flushing duration", 2018 International Conference on Digital Arts, Media and Technology (ICDAMT), Phayao, 2018, pp. 143-146.

[8] Mithya V, Divya Prabha N, Sisma Samlein S, Madhumitha M, "Smart Toilets using Turbidity Sensor", International Journal of Innovative Technology and Exploring Engineering, Vol-8, Issue-5S, March 2019, pp. 413-417.

[9] Pranali Sonekar, Aishwarya Surwayanshi, Kalyani Chandurkar, "Smart Sensible Washrooms", International Journal for Research in Applied Science \& Engineering Technology, Vol-7, Issue V, May 2019, pp. 4036-4037.

[10] K. Osathanunkul, K. Hantarkul, P. Pramokchon, P. Khoenkaw and N. Tantitharanukul, "Design and implementation of an automatic smart urinal flusher", 2016 International Computer Science and Engineering Conference (ICSEC), Chiang Mai, 2016, pp. 1-4.
[11] K. Osathanunkul, K. Hantrakul, P. Pramokchon, P. Khoenkaw and N Tantitharanukul, "Configurable automatic smart urinal flusher based on MQTT protocol”, 2017 International Conference on Digital Arts, Media and Technology (ICDAMT), Chiang Mai, 2017, pp. 58-61.

[12] Nafeesa Muntashar, Sahana K N and Saniya Shilledar, "Smart Urinal Mech-Automatic Flush", Journal of Emerging Technologies and Innovative Research, Vol- 5, Issue-6, June 2018, pp. 655-658.

[13] S Mohamed Ashiq, K Karthikeyan, S Karthikeyan, "Fabrication of Semi-Automated Pressurized Flushing System in Indian Railway Toilet", International Journal of Engineering and Advanced Technology, Vol-2, Issue-3, February 2013, pp. 240-244.

[14] Dharmesh Katariya, Pratik Parik, Akshay Pincha, Gauri Lodha and Anita Borse, "Smart Toilet", International Journal of Electrical, Electronics and Data Communication, Vol-6, Issue-5, May 2018, pp. 71-74.

[15] Sangwan S., Chugh N. and Tiwari P. K., "Smart Toilet- An IoT Solution", International Journal of Advance Research in Science and Engineering, Vol. 6, Issue 11, Nov. 2017, pp. 647-651.

[16] M. Ra, M. S. Muhammad, C. Lim, S. Han, C. Jung and W. Kim, "Smartphone-Based Point-of-Care Urinalysis Under Variable Illumination," in IEEE Journal of Translational Engineering in Health and Medicine, vol. 6, 2018, pp. 1-11.

[17] J. Bae and H. Lee, "User Health Information Analysis With a Urine and Feces Separable Smart Toilet System," in IEEE Access, vol. 6, 2018 pp. 78751-78765.

[18] J. Huang, S. Yu and H. Syu, "Development of the Smart Toilet Equipment with Measurements of Physiological Parameters," 2012 9th International Conference on Ubiquitous Intelligence and Computing and 9th International Conference on Autonomic and Trusted Computing, Fukuoka, 2012, pp. 9-16.

[19] Keskar Vinaya N., "Electricity Generation Using Solar Power", International Journal of Engineering Research \& Technology (IJERT), Vol. 2, Issue 2, February 2013, pp. 1-5.

[20] J. Aggarwal and M. L. Aggarwal, "Harnessing Solar Energy For Every Home: Energy Saving Applications", Hindawi Publishing Corporation, Conference Papers in Science, Vol. 2014, 2014, pp. 1-3.

[21] F. Umer, M. S. Aslam, M. S. Rabbani, M. J. Hanif, N. Naeem and M T. Abbas, "Design and Optimization of Solar Carport Canopies for Maximum Power Generation and Efficiency at Bahawalpur", Hindawi, International Journal of Photoenergy, Vol. 2019, 2019, pp. 1-8. 